\title{
Effects of topographic and geological features on building damage caused by 2015.4.25 Mw7.8 Gorkha earthquake in Nepal: a preliminary investigation report
}

Fawu Wang ${ }^{1 *}$, Masakatsu Miyajima ${ }^{2}$, Ranjan Dahal ${ }^{3}$, Manita Timilsina ${ }^{4}$, Tonglu Li ${ }^{5}$, Makoto Fujiu², Yohei Kuwada ${ }^{6}$ and Quanli Zhao ${ }^{5}$

\begin{abstract}
Background: The 2015.4.25 Gorkha earthquake affected about eight million people in Nepal. Most injuries and loss of life were due to building collapse and damage. This work aims to investigate the topographical and geological effects on the severe damage caused by this earthquake.

Findings: In one-week field investigation in the earthquake-affected areas, several severely damaged areas with different topographic and geological features were surveyed, as well as the site of Kaligandaki River landslide dam failure. Some general tendency related to the building damage and landslide dam failure was obtained.

Conclusions: Through the field investigation, it was found that geological and geomorphological characteristics of a site, combined with the structure feature of the building, such as the short column effect, amplified the seismic vibration and caused severe building collapse and damages, i.e., 1) For buildings on flat area consisting of lacustrine deposit or diluvial deposit, resonance effect might be the main reason, while for the buildings on the top of hills or narrow ridges, topographic effect and sometimes, short column effect should take the main responsibility; 2) For buildings located on the gentle slopes or landslides, the settlement in the infill side caused by the strong seismic vibration can be the main reason; 3) Besides of the building failure on lacustrine deposit, failure patterns in three types of topographic and geological features, i.e., narrow ridges formed by landslides, diluvial deposits and alluvial fans, and landslides, were proposed as the possible mechanism of the building damage caused by the earthquake. For landslide dam failure, it was found that landslide dam could easily breach or collapse, when the landslide-dam-deposits were fine.
\end{abstract}

Keywords: Gorkha earthquake, Investigation, Topographic effect, Resonance effect, Landslide dam, Building damages

\footnotetext{
* Correspondence: wangfw@riko.shimane-u.ac.jp

${ }^{1}$ Department of Geoscience, Interdisciplinary Graduate School of Science and

Engineering, Shimane University, Nishikawatsu 1060, Matsue 690-8504, Japan

Full list of author information is available at the end of the article
} 


\section{Background}

The Gorkha earthquake occurred at 11:56 NST on 25 April 2015. The focal depth is about $15 \mathrm{~km}$. The epicenter is $77 \mathrm{~km}$ northwest of Kathmandu. Based on the information from the United Nations, about eight million people have been affected by the strong earthquake in Nepal, which is more than a quarter of the Nepal's population (Goda et al. 2015; Dahal and Timilsina 2015).

To understand the damage caused by the earthquake, and find a solution to mitigate the geodisasters in Nepal, a preliminary investigation on the 2015 Gorkha earthquake was conducted from 2 to 9 June 2015.

Figure 1 shows the route taken for this investigation. In addition to the investigation on the cultural heritage and building damage in Katmandu city, Gorkha Palace, Chautara town, and Sankhu town, we also visited Kaligandaki River landslide dam, and conducted measurements and investigation. The linear distance traveled for this investigation was about $250 \mathrm{~km}$.

In this report, the observation, investigation and measurements on the following five geological settings are described in detail respectively.

1. Cultural heritage and building damage in Katmandu city (located on lacustrine deposits)

2. Building damage in Gorkha Palace, Chautara and Changu Narayan (located on a narrow mountain ridge)

3. Building damage in Sankhu (located on an alluvial fan)
4. Building damage in Purano Naikap (located in a possible landslide area)

5. An earthquake-induced landslide dam in Kaligandaki River

\section{Methodologies and findings}

Investigation on cultural heritage and building damage in Katmandu city (lacustrine deposits)

According to a previous study (Sakai 2001), lacustrine deposits are widely distributed in the Katmandu valley. The maximum depth reaches $600 \mathrm{~m}$, and the average thickness at the center of the Katmandu basin is about $200 \mathrm{~m}$. Many ancient buildings and temples were severely damaged or destroyed in Katmandu city.

\section{Damage at the Swyambhunath world heritage site}

Figure 2 shows the topography of the Swyambhunath World Heritage site and its surrounding area. It is located on an isolated hill near the mountainous area in the west side of Kathmandu city. On the hill, there was a pond named Peace Pond. The local Buddhist monks in the temple told us they have felt strong shaking during the earthquake. In this investigation, we found distinctively crooked trees, known as "drunken" trees, widely distributed on the north slope of the heritage site (Fig. 3). These types of trees often indicate slope movement and probable slow-moving landslide activity, known as creep, a process which usually occurs over an extended period of time.

The Swyambhunath World Heritage site is located on the top of the hill. Figure 4 compares the world heritage site before and after the earthquake. It shows that the main temple in the middle was in a relatively

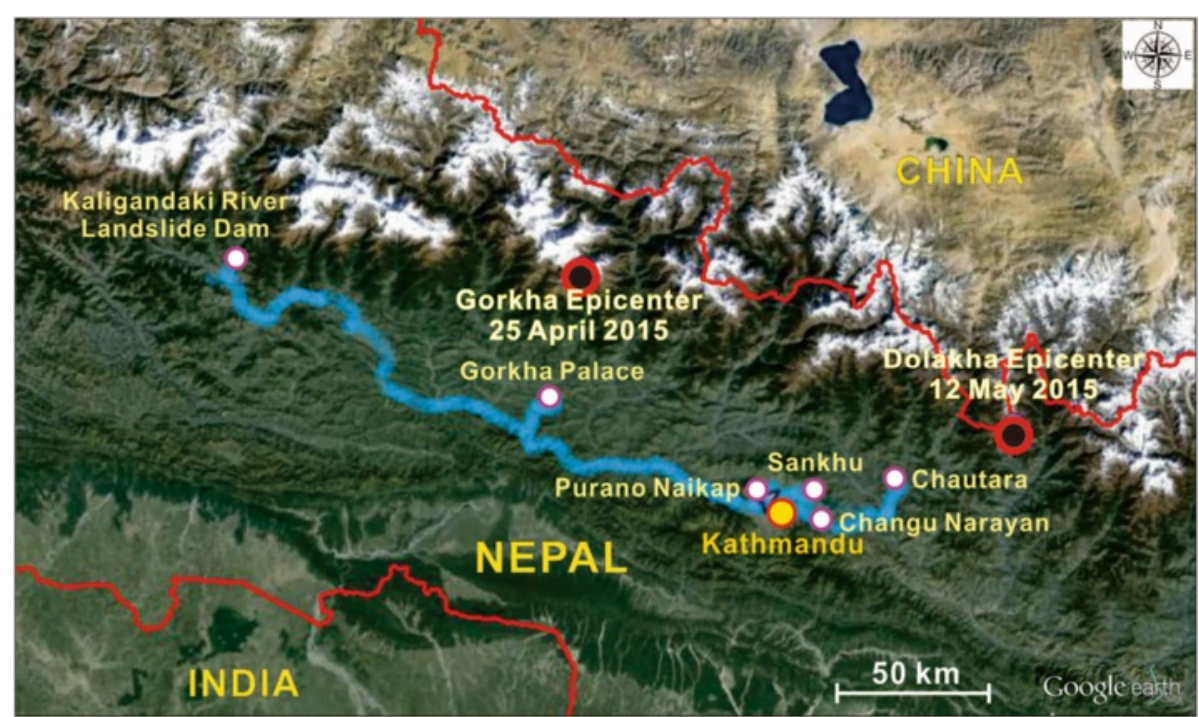

Fig. 1 The route of the investigation for the 2015 Gorkha earthquake, Nepal 


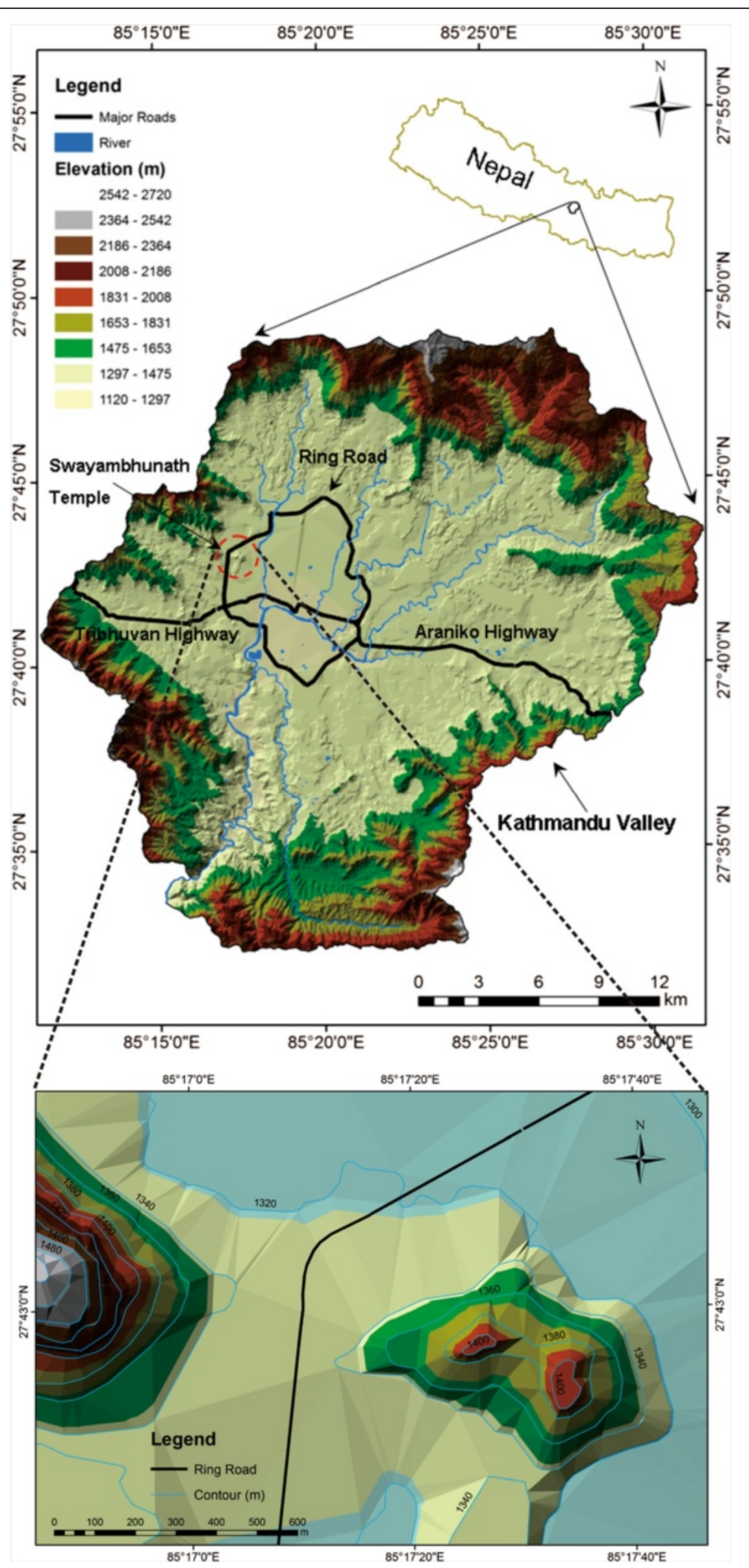

Fig. 2 The location map of the Swyambhunath World Heritage site and surrounding area 


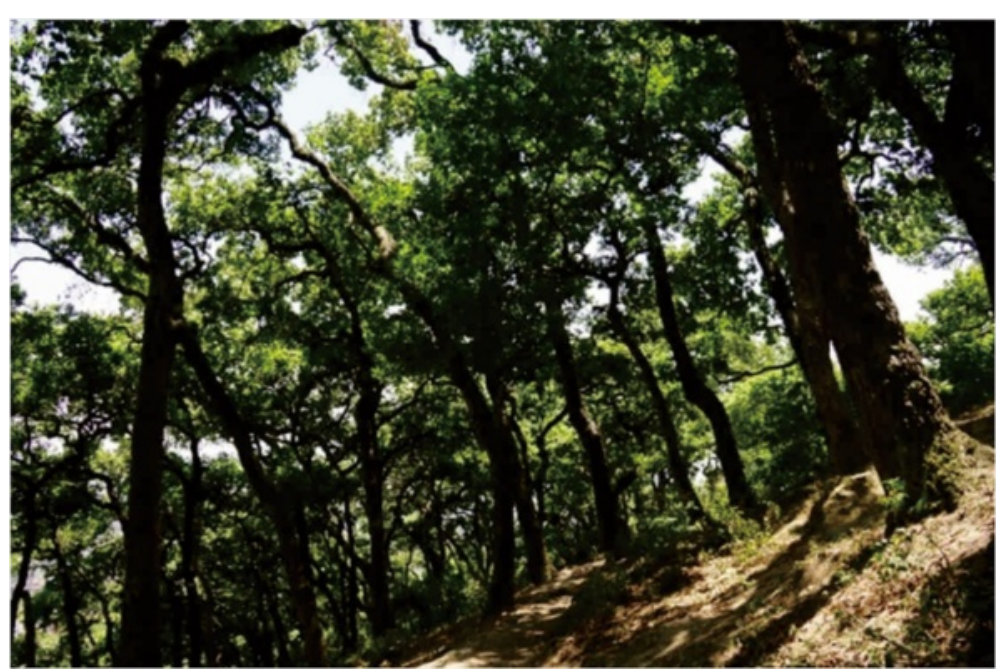

Fig. 3 "Drunken" trees on the north slope of the Swyambhunath World Heritage site, indicating slow slope movement

good condition, while the temples surrounding it and located near the hill slope suffered collapse.

During the investigation, it is found that the damages are more severe where the buildings and temples are closer to the slope. It may mean that the shaking is much stronger at the slope shoulder than at the mountain top. After the investigation in the same site, Hashash et al. (2015) pointed out that the topography effects refer to the modification (frequently amplification) of incident ground motion due to energy focusing effects at convex topographic features (hills, ridges, canyons, cliffs, and slopes), complicated subsurface topography (sedimentary basins, alluvial valleys), and geological lateral discontinuities (e.g., ancient faults, debris zones). These features can significantly alter the intensity, frequency content and duration of ground shaking during earthquakes compared to the shaking that the same site would have experienced, had it been on flat ground. In the Swyambhunath site, the topographic effect of hills and slopes may have occurred.

\section{Damage in Dharahara and Durbar Square}

Dharahara and Durbar Square areas are the central areas of Kathmandu city. It is also an attractive resort with many famous temples and buildings. During the

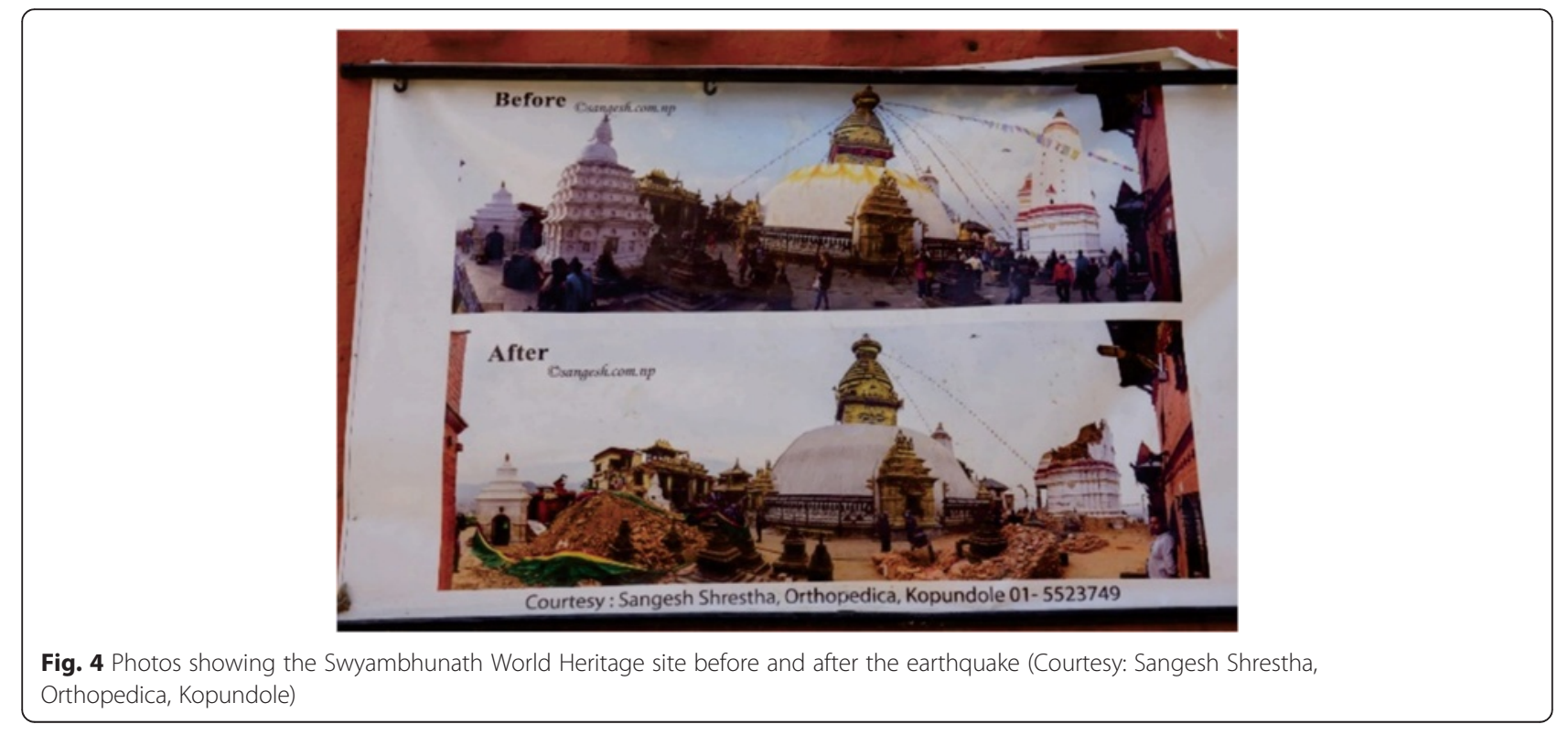



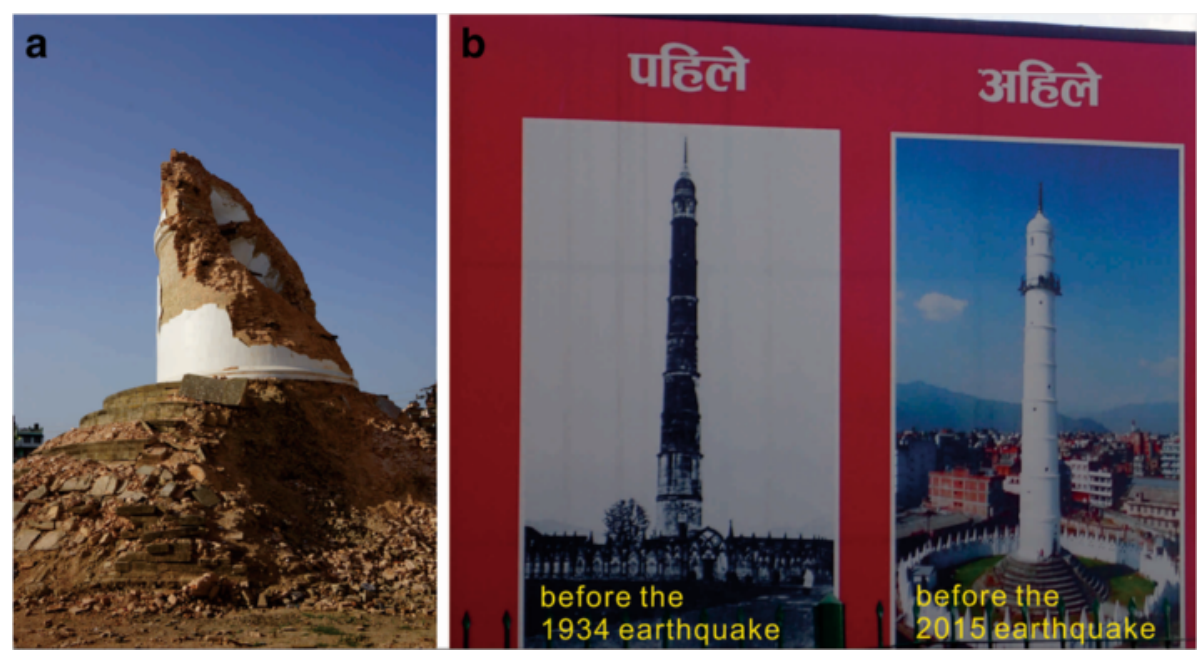

Fig. 5 The collapse of Dharahara tower. a damaged Dharahara tower; and (b) a poster showing two photos of the tower before the 1934 and 2015 earthquakes

earthquake, those ancient temples and buildings suffered heavy damage.

During the earthquake, the Dharahara tower collapsed and more than 180 people lost their lives. The main body of the tower collapsed under the attack of this earthquake, only the base remained (Fig. 5a). According to Wikipedia (2015), the Dharahara tower, was a nine-story, $61.88 \mathrm{~m}$ tall. The former Dharahara tower was built in 1832 . The tower had a spiral staircase with 213 steps. It can be seen from Fig. 5(a) that the main trunk of the tower is made by bricks with lime mortar cemented, which is weak for seismic action.

In Durbar Square, it is full of temples and cultural architectures. During the earthquake, lots of ancient temples were damaged severely (Fig. 6). Some of them were completely destroyed (Fig. 7). In Fig. 7, the
Kashthamandap temple, from which the Kathmandu city got the current name, was completely destroyed.

According to the fact sheet of the earthquake by USAID (2015), 510,762 houses were destroyed, and 291,707 houses were damaged by the Earthquake. Durbar Square area is one of the most severe areas suffered the damages (Fig. 8). Cracks appeared on the walls of those buildings, and the residents still lived in the damaged buildings and used wooden and metal sticks to support them.

Through a study of local amplification effect of soil layers on ground motion in the Kathmandu Valley using microtremor analysis, Paudyal et al. (2012) concluded that the multiple amplified frequencies in a particular area can create a resonance effect both for low rise and tall buildings. They pointed out that the behavior of the surface layer as well as the layer underneath should be taken into consideration for
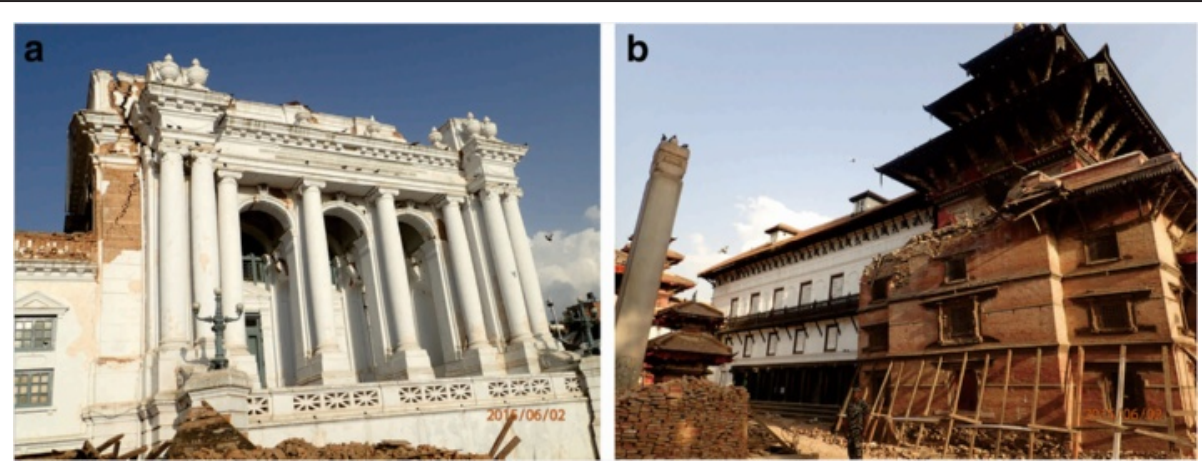

Fig. 6 Damages on temples and buildings near the Durbar Square. a Gaddi Baithak in Basantapur Durbar Square; b one building in Hanuman Dhoka 

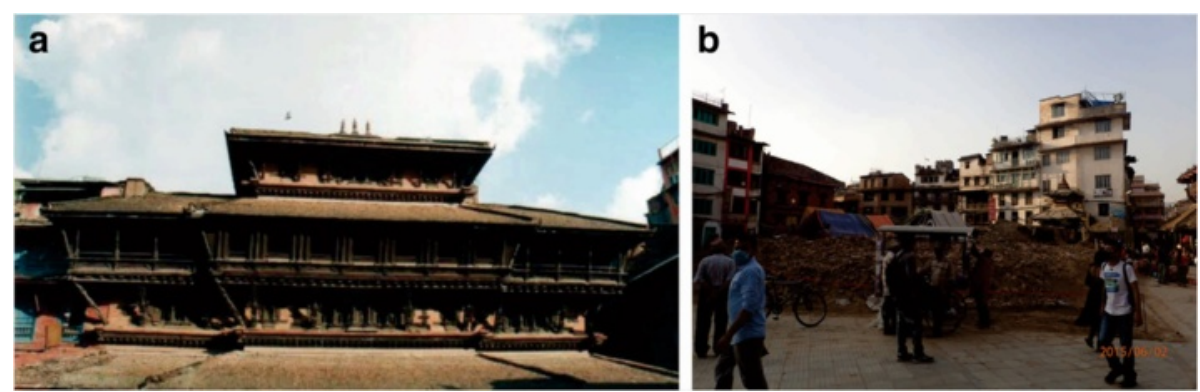

Fig. 7 The collapse of the Kashthamandap temple. a The temple before the earthquake; $\mathbf{b}$ the situation after the earthquake

seismic risk studies in the Kathmandu Valley. Because of the resonance effect, the low-rise to medium-rise buildings, and improperly designed buildings were selectively damaged.

From a viewpoint of long-term safety of the buildings, reconstruction of these building is recommended. However, the number of damaged buildings is so large that the budget required to rebuild them may have to be evaluated by the government.

\section{Building damage in Gorkha Palace, Chautara and Changu Narayan (narrow mountain ridge)}

The residential areas located on narrow mountain ridges suffered severe damage. This damage may be caused by the topographic amplification effect of the narrow mountain ridge. During the investigation, we visited three typical sites: Gorkha Palace, Chautara town and Changu Narayan. The following gives the damaging situation in details.

\section{Damage in Gorkha palace}

Gorkha Palace is the source of the Shah dynasty, and it is a very important culture heritage in Nepal. Because it is located near the epicenter, it was exposed to different effects of the earthquake.
Figure 9 shows the topographic condition of the Gorkha Palace. The Gorkha Palace is located on the top of a narrow ridge, surrounded by many landslides in different sizes, some of them being very large. In the area of Gorkha Palace, two main buildings were built along a narrow ridge of the hill. Figure 10 shows the main buildings, which featured a small red building and a grey fence around the palace. The so-called palace actually only consisted of these brick buildings. From Fig. 10, it can be observed that the cracks on the fence and the main building were running along the ridge direction. Looking at the roof tiles, falling-down only occurred on the sides parallel to the running direction of the hill ridge. Comparing the damaging situation to the other buildings located at the toe of the hill, the damages happened in the palace were much more severe. This should be caused by the topographic amplification effect of the narrow mountain ridge.

\section{Damage in Chautara town}

Chautara town is one of the places that suffered the most severe damages during the earthquake. The whole town was located along the Dolalghat-Chautara highway, and its location somewhat coincided with

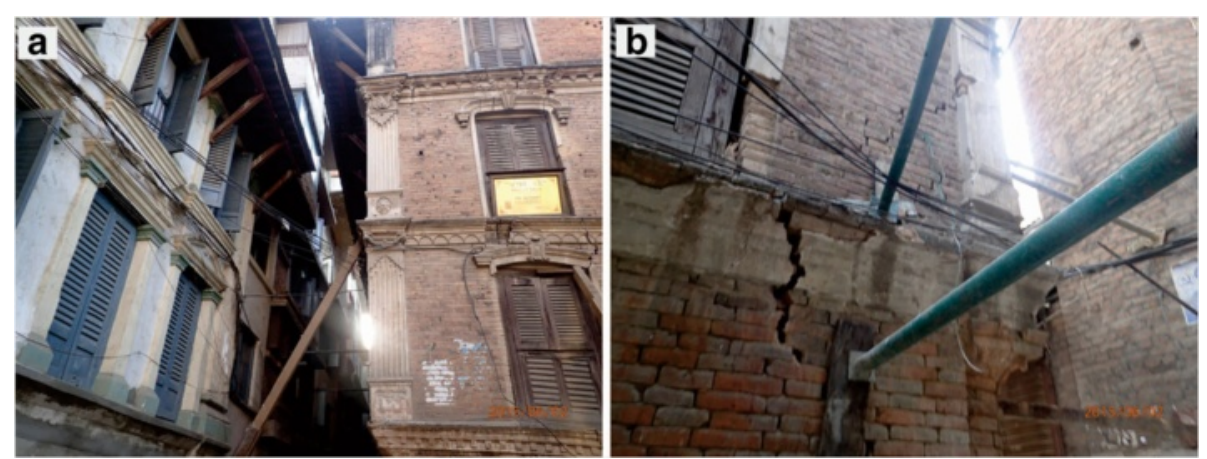

Fig. 8 Heavy damage occurred to the residential buildings in the Durbar Square area. a collapsed buildings supported by wooden sticks; $\mathbf{b}$ Cracks in the building and metal supporting sticks 

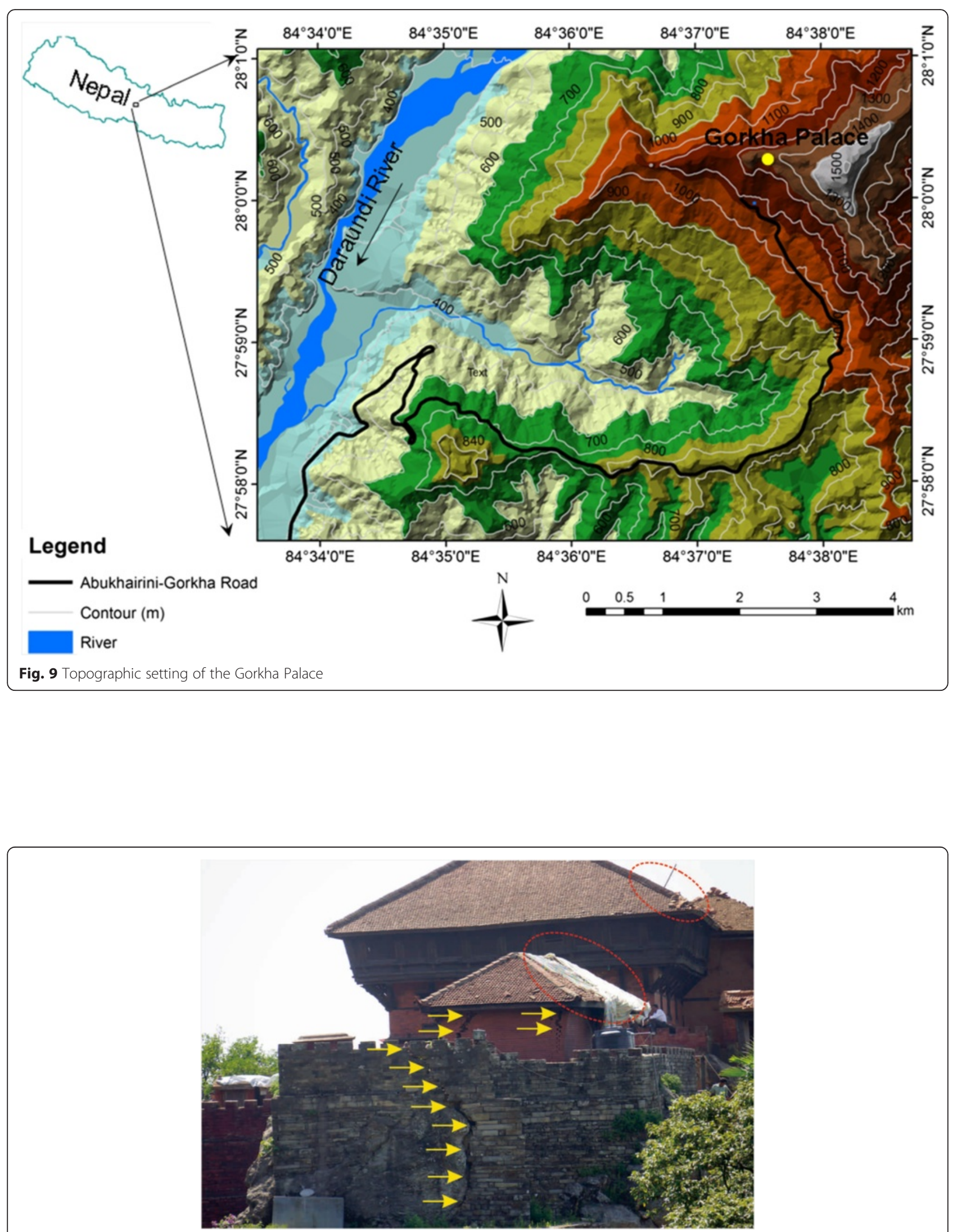

Fig. 10 Damage to one of the buildings and fence in the Gorkha Palace, shown by yellow arrows and red circles 


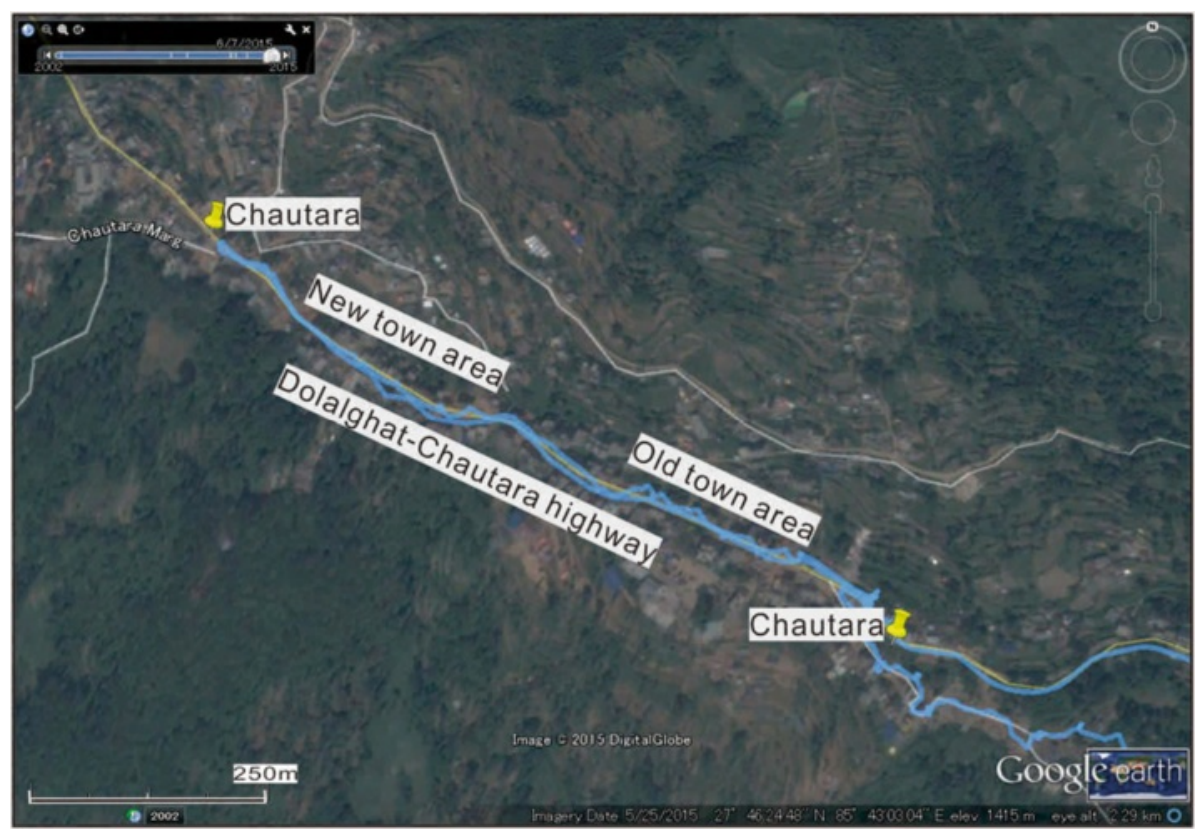

Fig. 11 Investigation route along the highway in Chautara town

the mountain ridges. Figure 11 shows the investigation route into the town, along the highway. It can be seen that the highway is located in the center of the town, and was sandwiched by the buildings along the highway. On the slopes at the two sides, stepplantation fields are widely distributed, and most of them shows evidence of landslides.

The Chautara town consists of two parts: old town and new town. In the old town area, the buildings had a simple structure with bricks and wooden slabs. In the new town area, concrete buildings were built three stories or higher. Figure 12 shows the damage in the old town area. More than $80 \%$ buildings were destroyed by the earthquake.

Figure 13 shows the damage in the new town area. The buildings were made by reinforced concrete, with three or more stories. Some of the concrete building had cracks at the first floor (Fig. 13a). Some of them completely collapsed (Fig. 13b), and some of them tilted to the slope side (Fig. 13c). Breakage had occurred even at the pillars of some buildings under construction (Fig. 13d). In the case shown in Fig. 13d, the so-called short column effect may have occurred. According to Murty (2016), poor behavior of short columns is due to the fact that in an earthquake, a tall column and a short column of same cross-section move horizontally by same amount. Because the short column is stiffer as compared to the tall column, it attracts larger earthquake force. Stiffness of a column means resistance to deformation. The larger the stiffness is, the larger the force required to deform it. If a short column is not adequately designed for such a

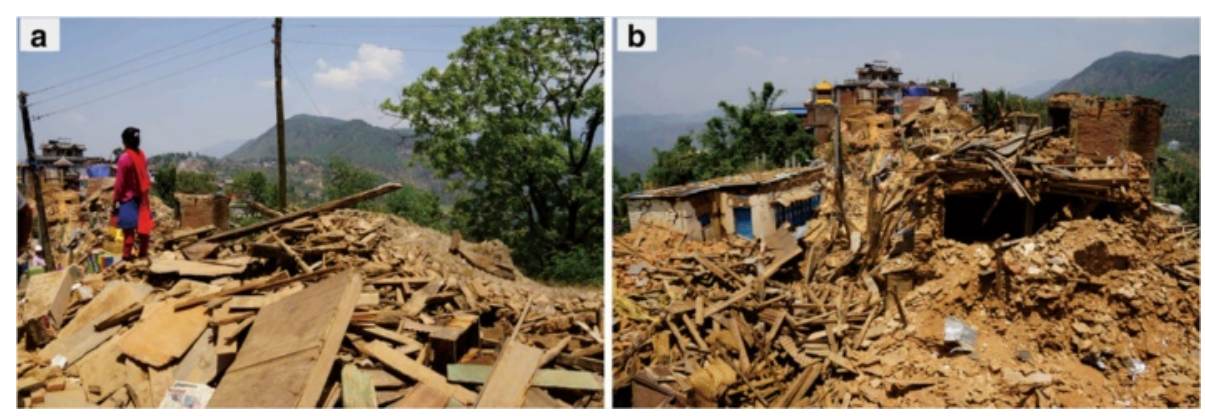

Fig. 12 Almost completely destroyed old town in Chautara. a Completely flattened buildings; b Destroyed buildings with standing walls 

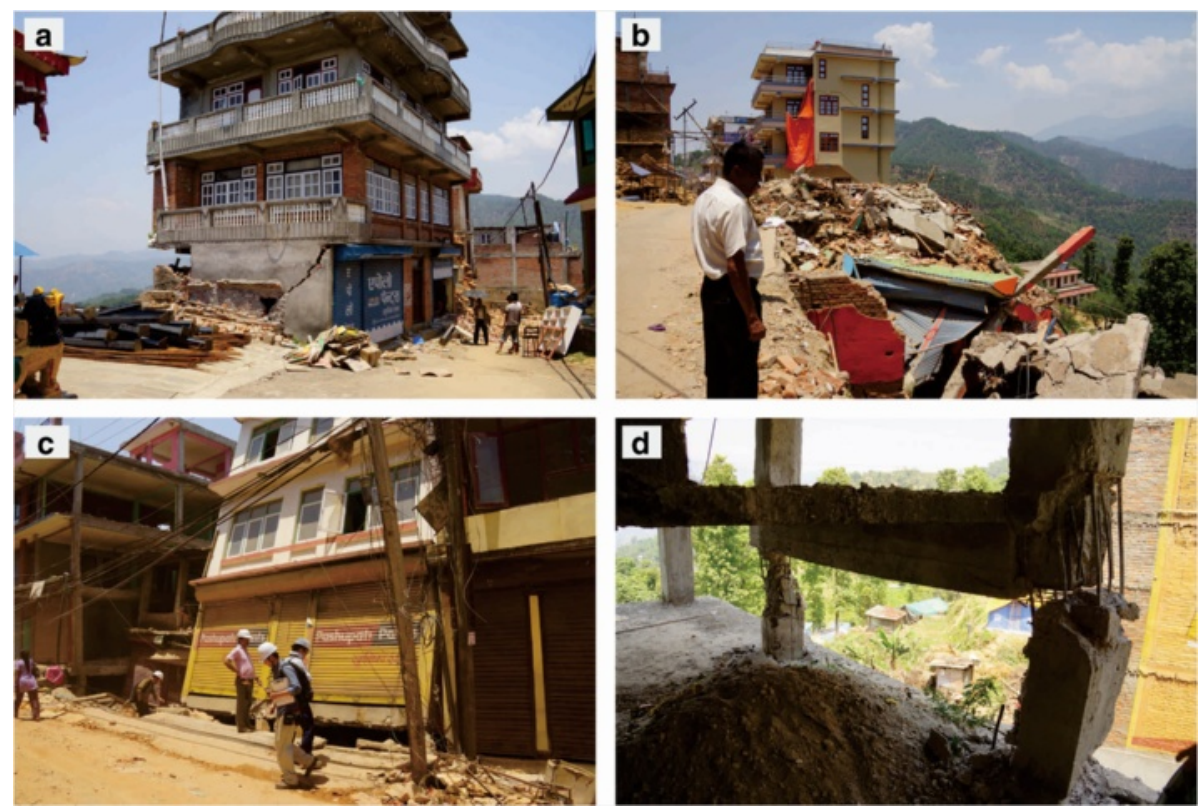

Fig. 13 Partially destroyed or damaged new town area in Chautara. a Cracks in the concrete building; b completely destroyed building; c building titled to the downslope side; $\mathbf{d}$ breakage in pillars of new uncompleted building

large force, it can suffer significant damage during an earthquake.

The damage to the Chautara town was very severe though it is far from the epicenter and earthquake fault. The reason may be the amplification of the narrow mountain ridge, combined with the special structure of the buildings built on the slope along the highway. However, looking from another side of the town, it seems like that the whole town of the Chautara might be located on a large-scale landslide. If it is true, the Chautara town should consider moving to a safer place; otherwise, it will most likely

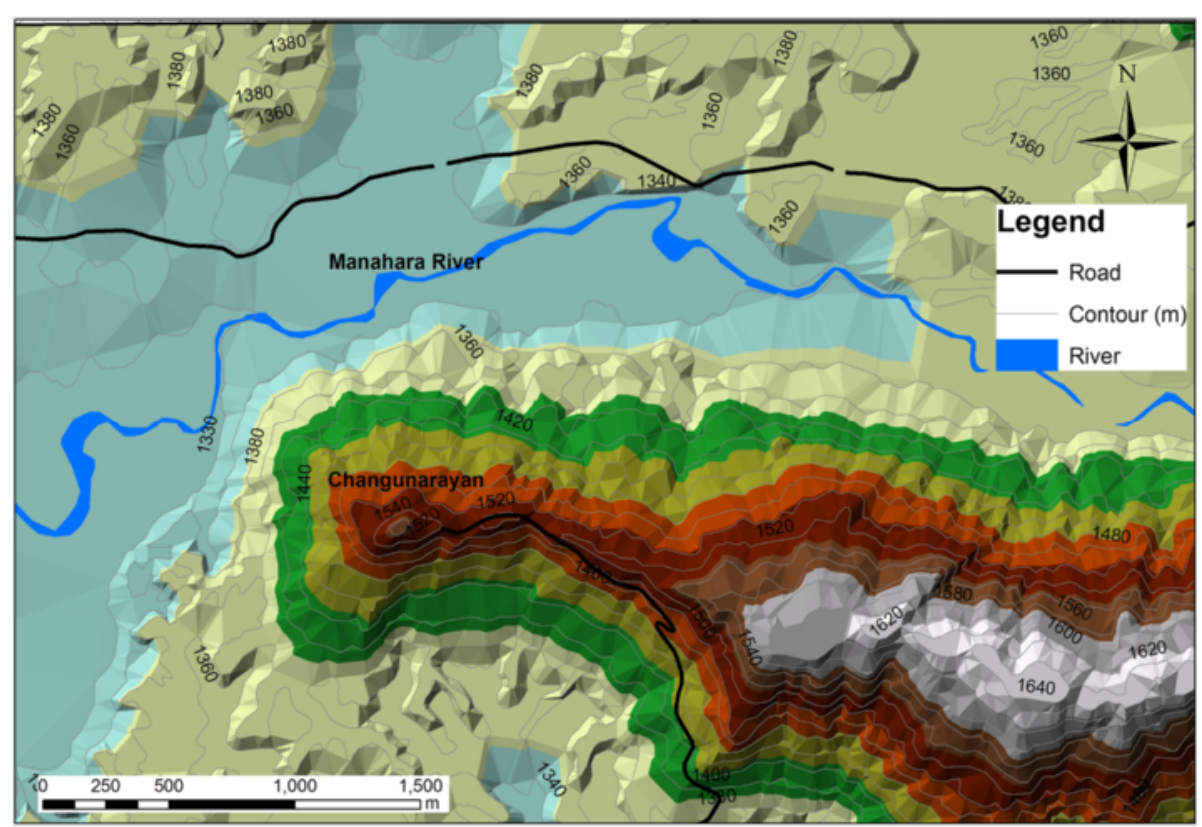

Fig. 14 Topography of Changu Narayan 

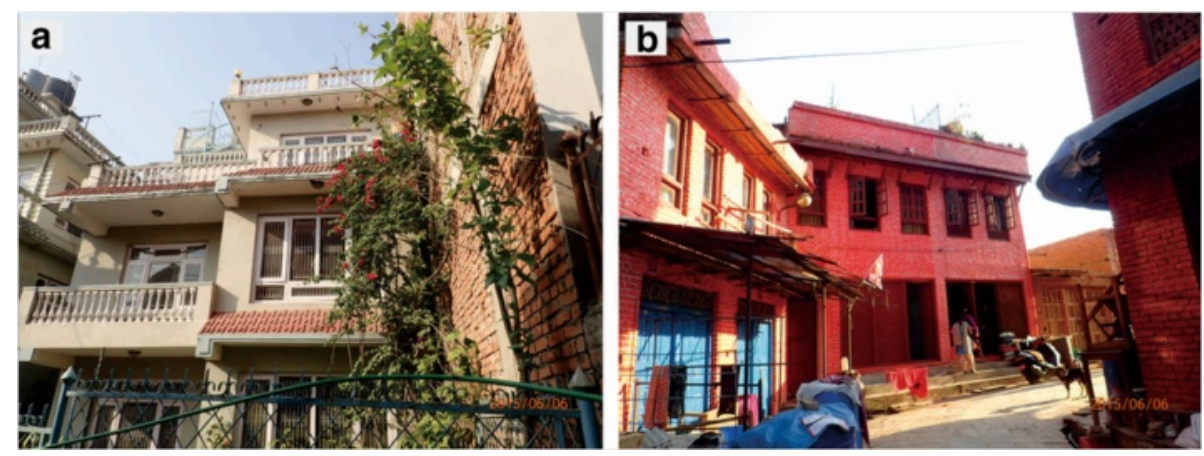

Fig. 15 Solid buildings in Changu Village. No obvious damage can be observed to these buildings $\mathbf{a}$ \& $\mathbf{b}$

suffer similar damage in the next large earthquake event. To solve this problem, more detailed investigation and landslide mapping are useful and effective.

\section{Damage to Changu Narayan temple at Bhaktapur}

The Changu Narayan temple is considered to be the oldest temple in Nepal. Figure 14 shows the topography of Changu Narayan. It is located on an isolated hill. At both sides of the hill ridge, typical topography of a landslide was confirmed.

Figures 15, 16 and 17 show the different buildings and their degree of damage in Changu village. The newly-constructed RC structure building has not suffered obvious damage during the earthquake (Fig. 15), while the old-style brick structure building collapsed or separated by cracks (Figs. 16 and 17). From the collapse sections or faces, it can be found that the mortar was sparse and inadequate.

\section{Building damage in Sankhu (Alluvium fan)}

Sankhu area suffered from an extreme damage to the residential buildings. Figure 18 shows some typical collapses occurred in different buildings in this area. The old buildings with brick structure completely collapsed or were severely damaged. While on the new buildings with concrete slabs in the brick structure or reinforcement by concrete on the walls, inclining occurred or X-shaped cracks were observed, indicating a strong vertical compression stress.

To find the reason why the building were more heavily damaged than the surrounding villages, we observed areas around the residential section and then traveled in a northerly direction. Figure 19 shows the trace of the investigation route. It is found that this area is an alluvial fan. At Position A, we found large boulders in the shallow valley, and flowing water (Fig. 20a). On the terrace, two-floors or higher building were in good condition. At position B, there were rice paddies, surrounded by concrete buildings of two to four stories. The damage at point B was not so severe. It was observed that the most severe damage occurred at the middle-lower part of the alluvial fan. It is estimated that at that part, ground deformation has been amplified by the specified soil layer structure, and caused the concentrated collapses in the old buildings.

\section{Building damage in Purano Naikap (landslide area)}

During the investigation, we were reported that some strong shaking and failure occurred to the residential buildings in Purano Naikap area (Fig. 21). This area
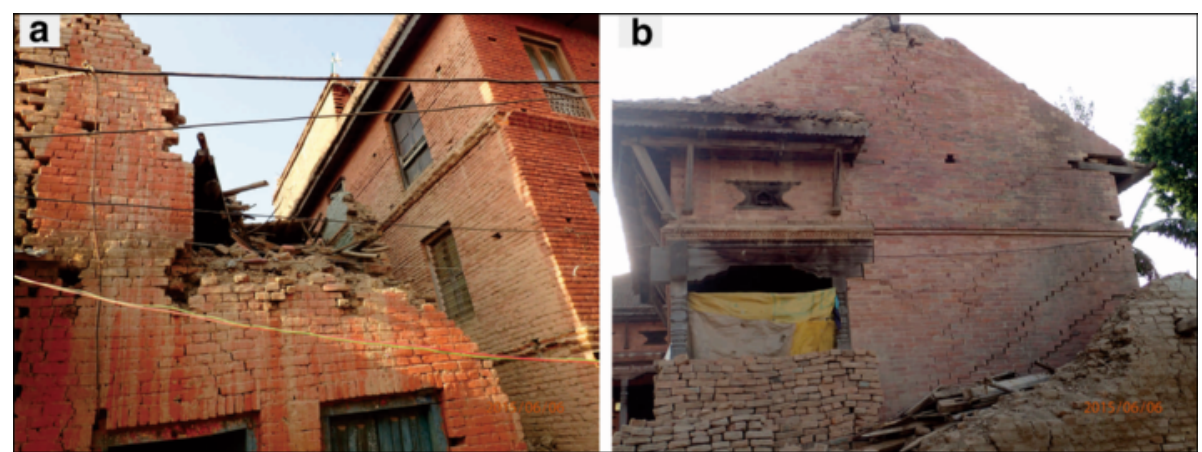

Fig. 16 Damaged buildings with brick structure in Changu village. a Heavily damaged brick building; $\mathbf{b}$ cracks in the brick building 

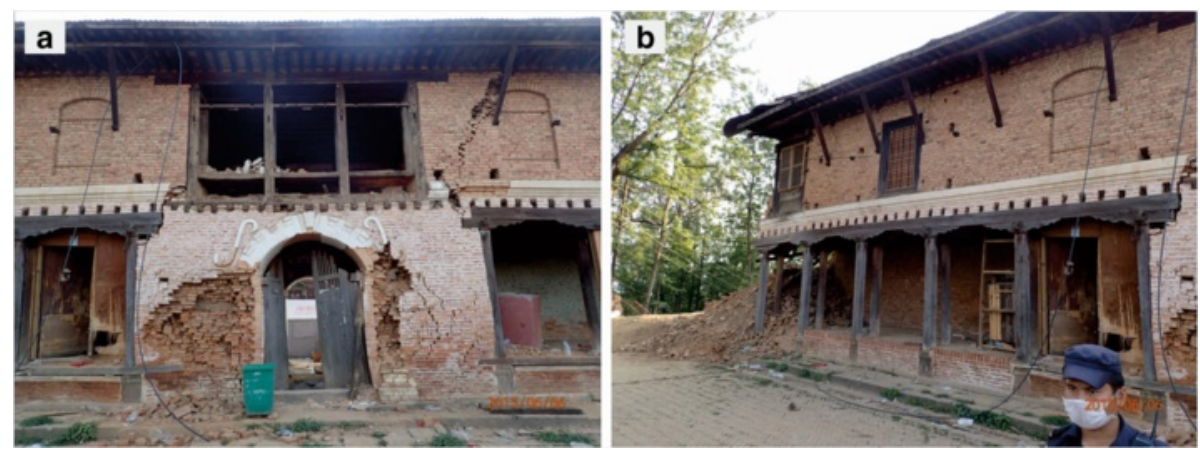

Fig. 17 Damages occurred on the main gate building at the entrance to Changu Narayan. a Collapse around the main gate; b Collapse at the two sides of the gate building

is located at southwest part of the Kathmandu basin and inclined to the basin center. As can be seen from Fig. 22, this area is occupied by residential buildings and agriculture fields on gentle slopes.

Figure 23 shows some typical damages to residential buildings in this area. A common tendency can be found in the nature of these damages, i.e., collapse or cracks mainly occurred at the downslope side of the buildings. Even there were no permanent deformation left on the ground after the earthquake, the severe damaged building were located in a limited area. We estimated that under the limited area, a landslide may exist. When the buildings were built on a probable landslide, the ground shaking might be much stronger than the surrounding area, and caused more severe damage on the buildings.

\section{Landslide dam in Kaligandaki river}

During the investigation, we had chance to visit a landslide dam in Kaligandaki River, learned of a successful story as how local government and people cooperated and prevented a possible geo-disaster. In Kaligandaki river of Myagdi District at Baisari along the border of Bhagawati and Ramche VDCs (Village Development Committee), about $110 \mathrm{~km}$ west to the epicenter of the Gorkha earthquake, at 11:10 of 22 May 2015 (about one month after the major shock), a small-scale rock fall occurred from a steep slope.
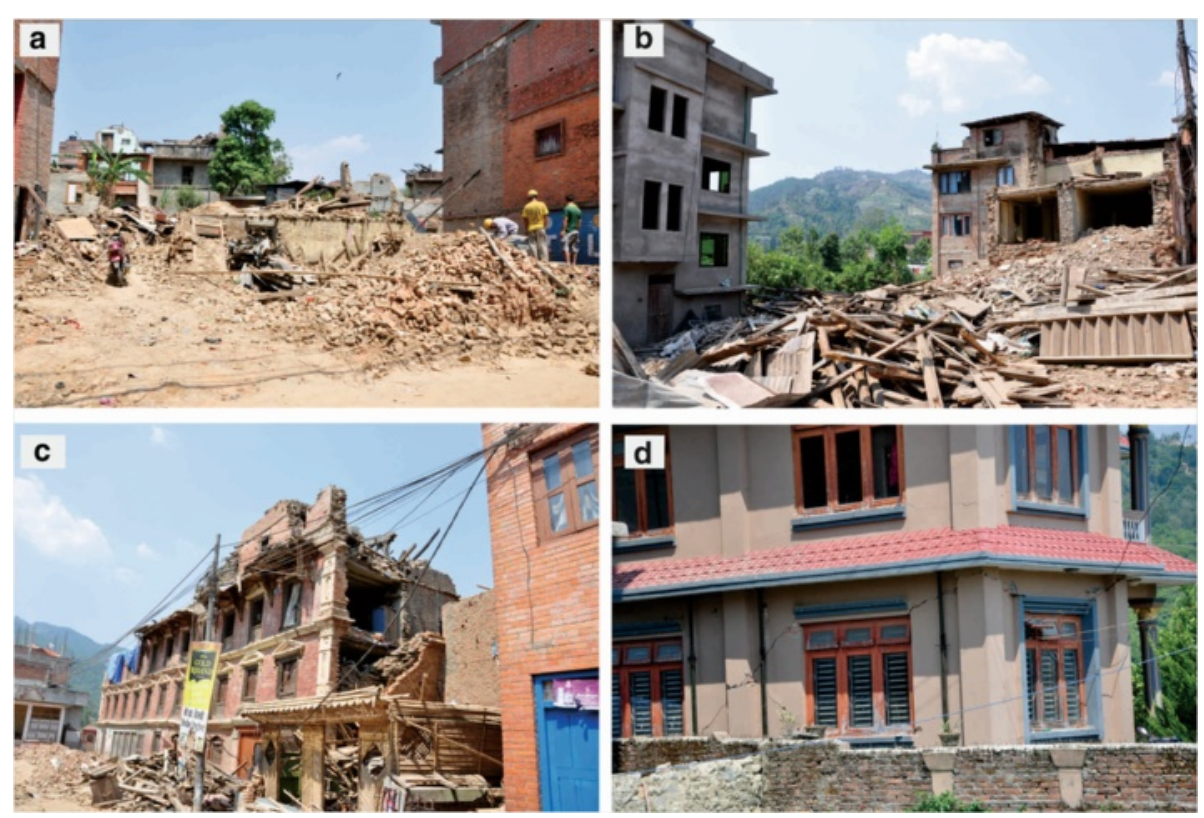

Fig. 18 Building damage situation in Sankhu area. $\mathbf{a}$ and $\mathbf{b}$ Completely destroyed wooden and brick buildings; $\mathbf{c}$ Partial collapses of a three-story building; $\mathbf{d} X$-shapes cracks in a new concrete building 


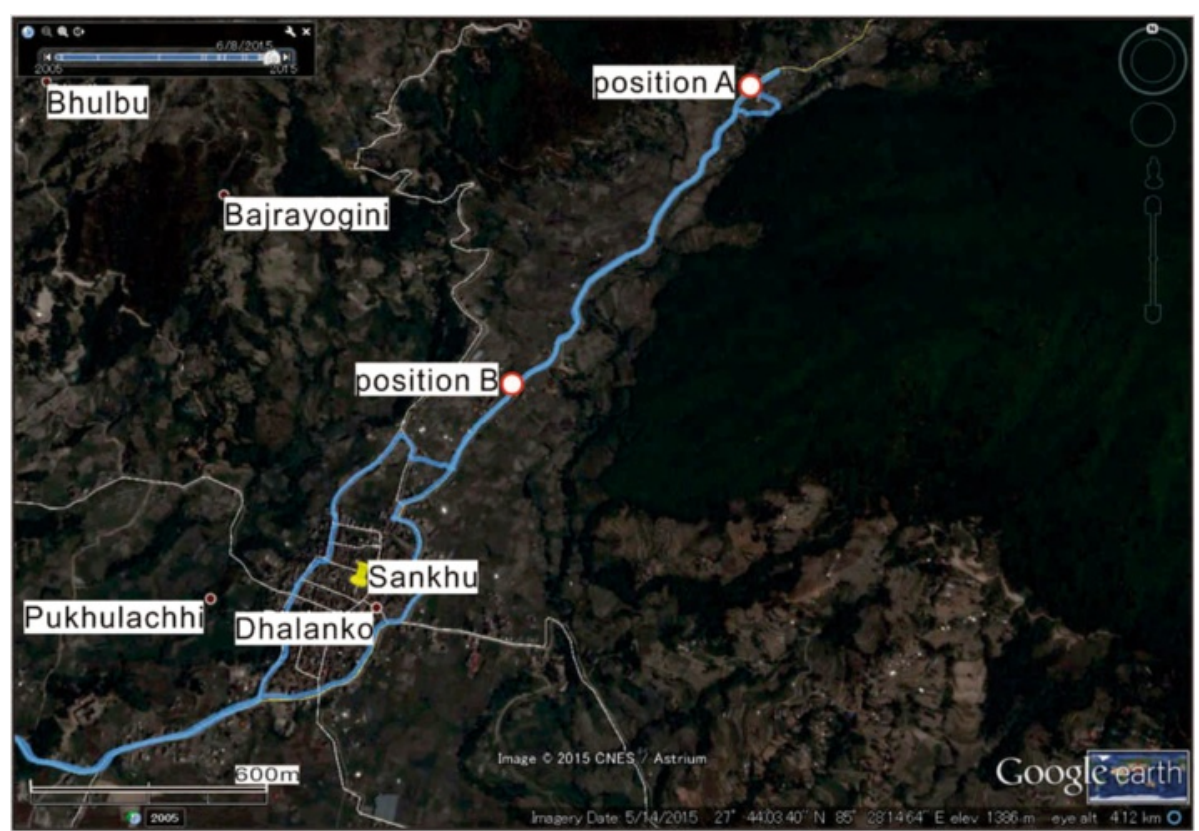

Fig. 19 Investigation route around the Sankhu area

After the small scale rock failure, the Central District Officer (CDO) of Myagdi and Chief of Department of Soil Conservation visited the site and climbed the slope for confirmation on slope deformation. During the visit, they noticed a scarp of more than $2 \mathrm{~m}$ on the mountain top and understood the critical situation of slope, then they forced the local people to move to safe place. Figure 24 shows fresh cracks developed in the upslope area. The locals were unwilling to move at the beginning as they said that it is normal and they have been facing such rockfall every year. However, the $\mathrm{CDO}$ insisted and forced them to leave and resettle in temporary shelters with the help of Nepal Army. Nearly 38 hours later, a big event of rock fall happened at the place and blocked the Kaligandaki River, buried all 27 houses, at 1:30 am of 24 May 2015. The collapsed debris deposited in the valley near the toe of the rockfall slope, dammed the valley, and formed a landslide dam lake.

Fortunately, before the major slope failure happened, the local authority understood the situation and resettled the local people to safe place. 124 people living in the village that was located at the opposite side to the cliff were evacuated.

What we felt was interesting about this site is the timing of landslide failure. With the cooperation from the Nepal Army who conducted the evacuation during the landslide occurrence and landslide failure, we can build the time record of the whole process. Figure 25 shows
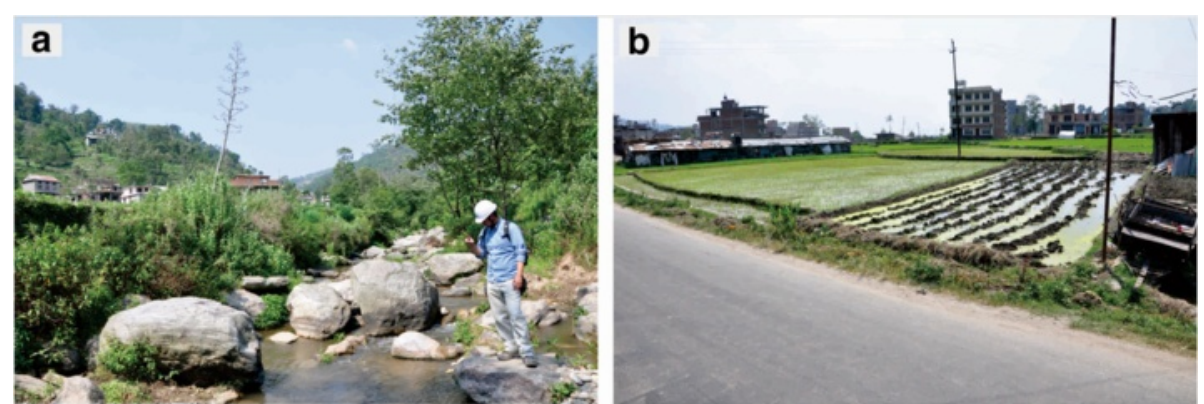

Fig. 20 Evidences of the alluvial fan near Sankhu. a Large boulders and flowing water in the valley; b Rice paddies at the upslope side of high buildings 


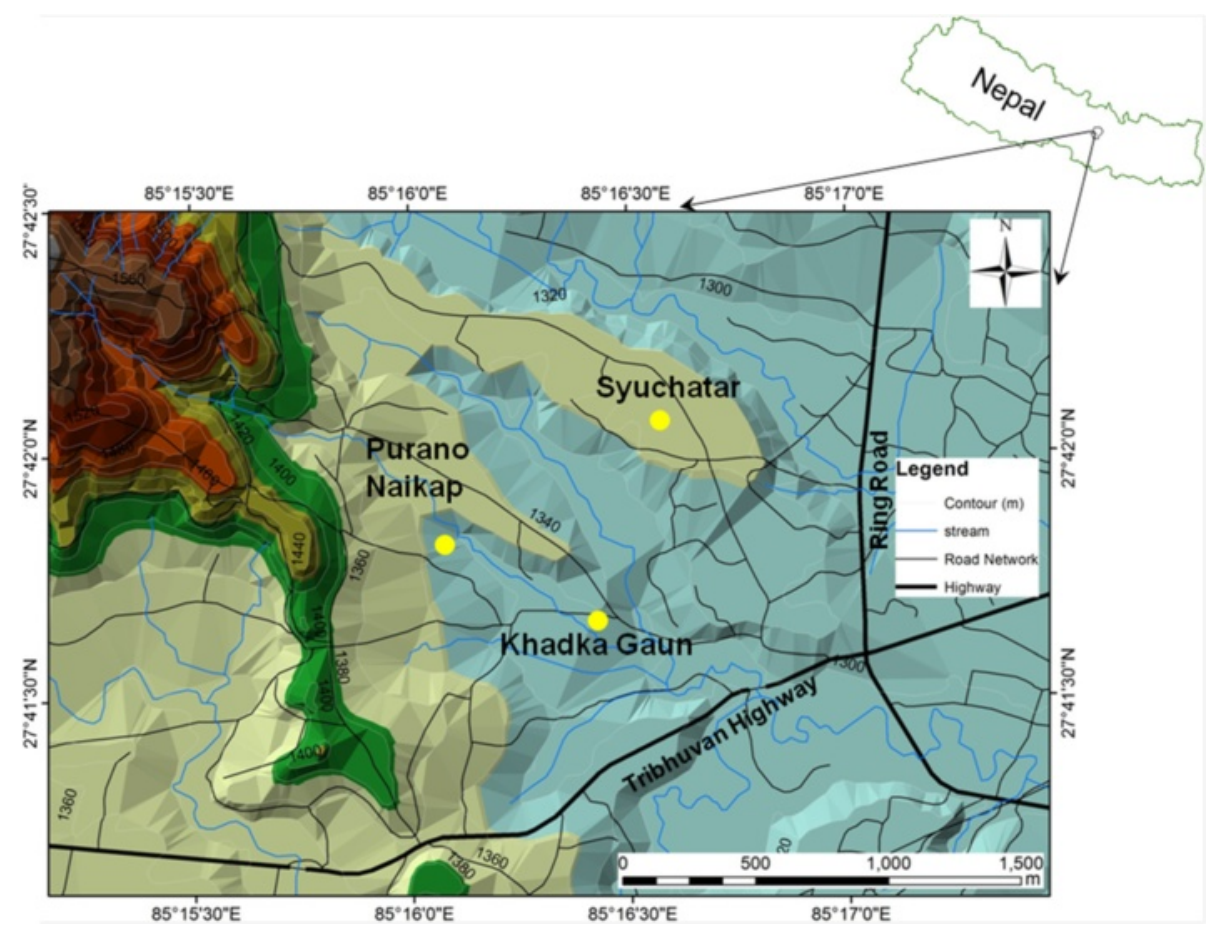

Fig. 21 Location of the Purano Naikap area

the time series images after the damming of the valley by the landslide, up until the complete collapse of the landslide dam.

The following is the time series.

11:10 of 22 May 2015: small scale rock fall occurred; 1:30 am of 24 May 2015: major rockfall occurred and the landslide dam was formed;

Around 16:00 of 24 May 2015: overflow started

(Fig. 25b);

Around 16:30 of 24 May 2015: landslide dam collapsed and the valley completely opened (Fig. 25c).
So roughly, it can be estimated that it took about 38 hours from the time of the small-scale rockfall to change into a major failure. It took 14.5 hours for the landslide dam lake to become fully filled, and 30 minutes for the landslide dam to complete collapse by overflow.

Figure 26 shows the situation for the landslide dam when the field investigation was conducted on 4 June 2015. The surface of the main cliff where the rock fall was generated was fresh, and the main cliff was steep. The channel was fully open and the water flow was rapid. During the investigation, the central longitudinal section was measured with a hand-held laser range

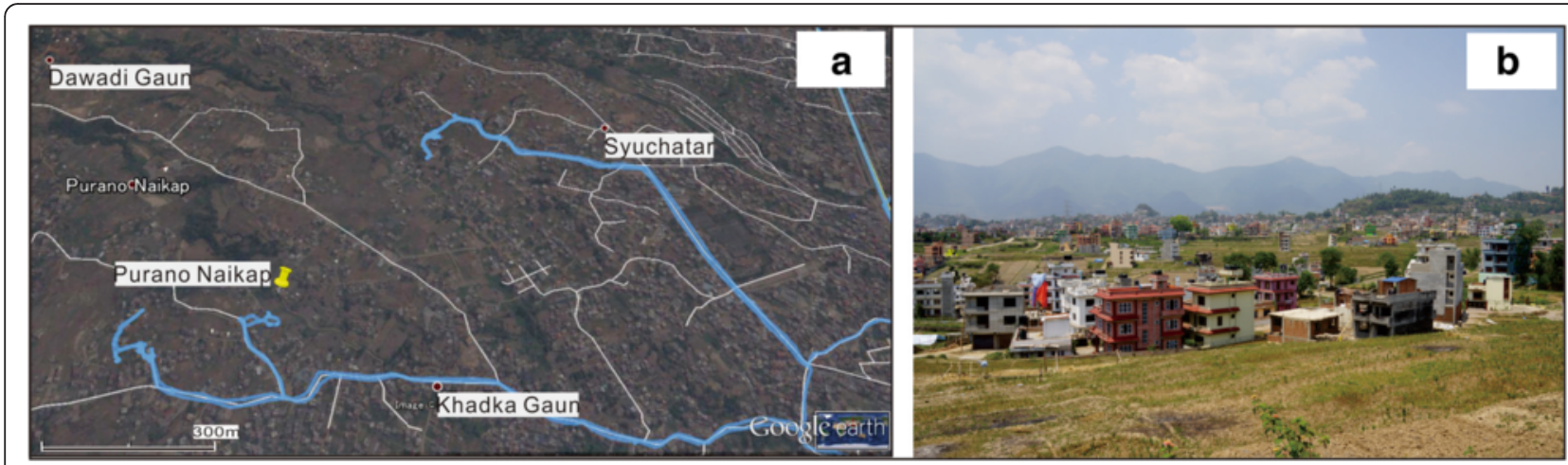

Fig. 22 Investigation route and topographic situation in Purano Naikap area. a the investigation route; b typical scene with residential buildings on gentle slopes 


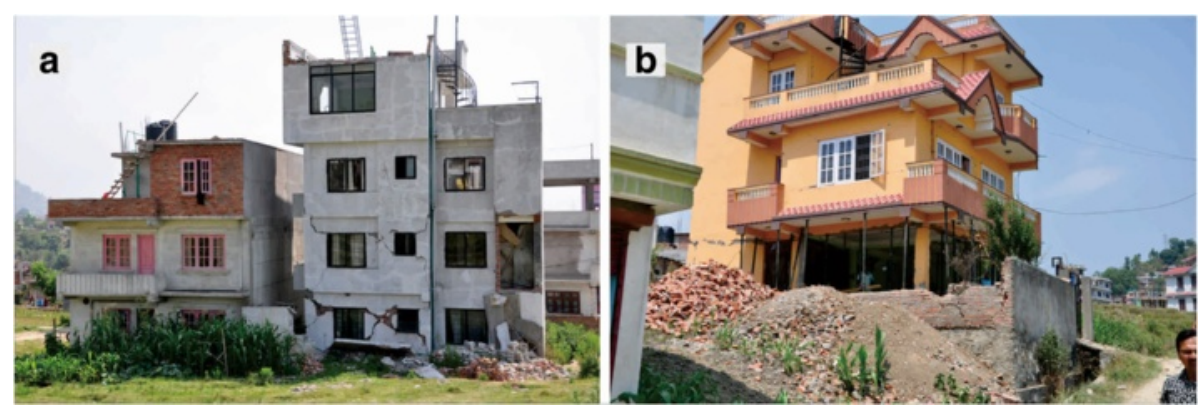

Fig. 23 Damages occurred on the residential buildings in Purano Naikap area. a X-shaped cracks in the first and second floors, some part collapsed; b Collapse occurred to one side of the first floor

finder. Figure 27 shows the results of the measurements. It can be seen from the figure that the height of the main cliff was higher than $660 \mathrm{~m}$, and the average slope angle was about 54 degree. The travel distance of the collapsed debris in the deposit area was about $200 \mathrm{~m}$, with an average slope angle of 21 degree. The maximum thickness of the landslide dam was estimated as $30 \mathrm{~m}$.

When we conducted the investigation at the Kaligandaki landslide dam, it was found that the landslide dam surface was covered by fine particles. The thickness of the fine particle layer was about $0.4 \mathrm{~m}$. It was so loose that footprints can be easily seen (Fig. 28a). Some soil samples were taken from the surface, and the grain size distribution analysis was conducted (Fig. 28b). It shows the soil sample is well graded silt, and the mean grain size is $0.02 \mathrm{~mm}$.

For the purpose of time prediction for landslide dam failure, we learned from that the collapse of the landslide dam by overflow only took 30 minutes. One of the possible reasons might be the crushing of the thin rock mass when the rockfall fell to the ground. The bedrock of the cliff is thin bedding phyllite which is relative soft and composed of fine scale-like minerals. Because of the strong collision from about a $700 \mathrm{~m}$ high position, the structure of the rock mass was pulverized. We concluded that the landslide dam consisting of loose deposits of the rockfall might be vulnerable for overflow, and the longevity of the dam will be short.

\section{Discussions}

When we got the news about the Gorkha earthquake, we have estimated that lots of landslides should be triggered, because the epicenter of the earthquake is located in the mountainous area. However, from our investigation and other related investigations (Collins and Jibson 2015a; Collins and Jibson 2015b; Hashash et al. 2015; Pandey and Mishra 2015), it is found that the amount of the large scale landslides is limited. However, lots of life was lost because of the collapse and damage of the buildings. Concerning the damage of building in hilly area by earthquake, through a case study of two cities in Indian Himalayas, Singh et al. (2015) concluded it is mainly due to the combination of a number of factors, including topographic
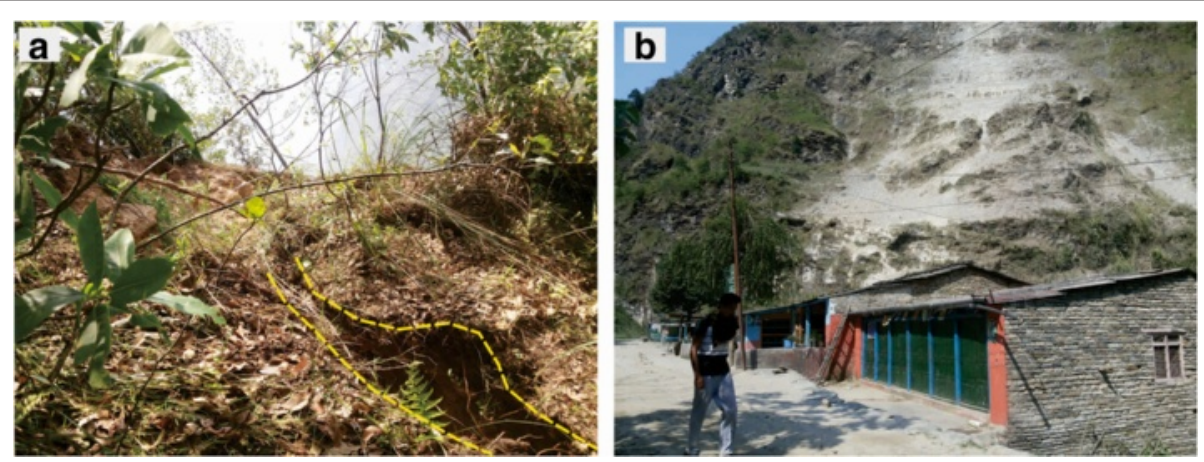

Fig. 24 The situation of the Kaligandaki village on 23 May 2015. a Large crack was evident on the top of the cliff; $\mathbf{b}$ small-scale rockfall occurred and rolled down along the slope causing dust (Photos supplied by Nepal Army) 

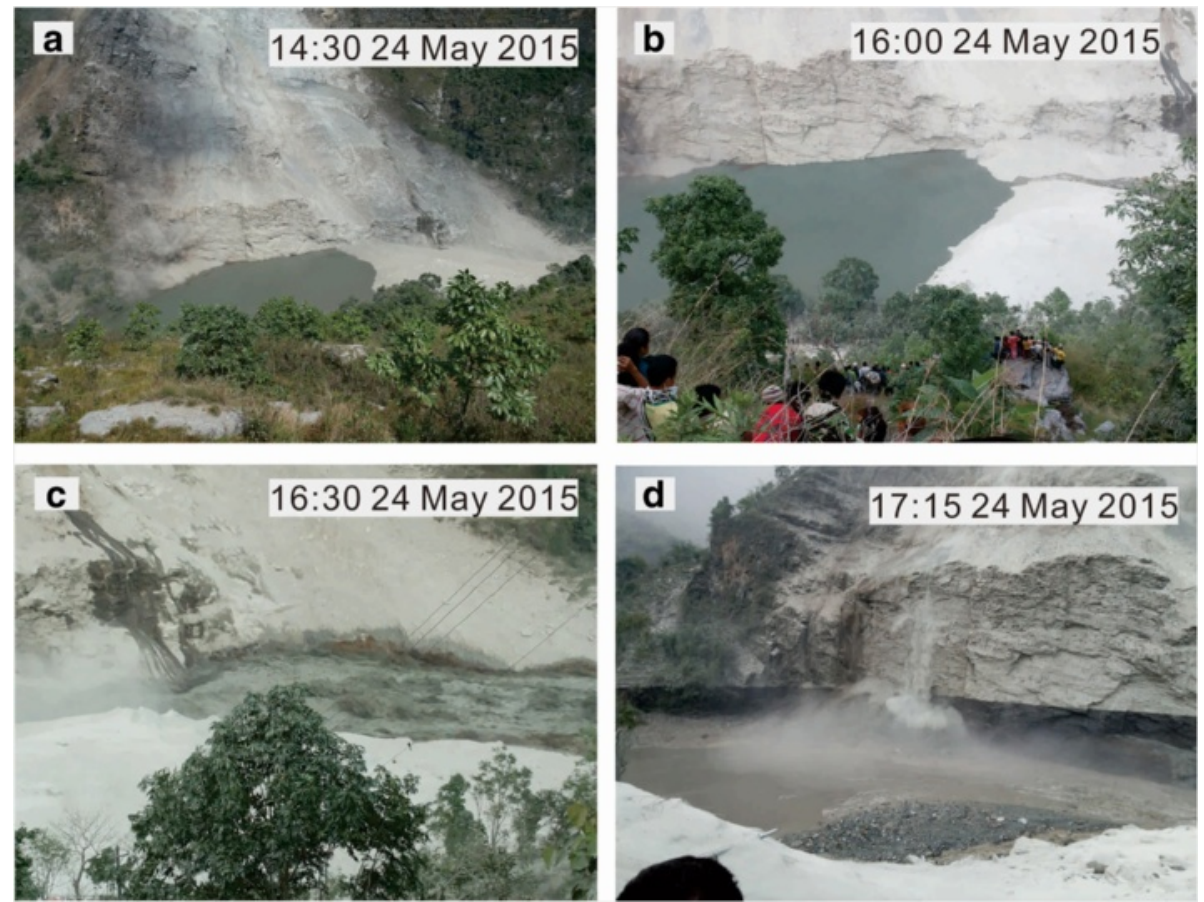

Fig. 25 Time series photos showing the process of landslide dam from its formation to complete failure (Photos supplied by Nepal Army). a the landslide dam before overflowing; b overflow occurred on the landslide dam around 16:00 of 24 May 2015; c collapse of the landslide dam around 16:30 of 24 May 2015; d the opened channel of the valley

amplification, earthquake triggered ground failure hazard and higher vulnerability of hill buildings due to irregular structural configurations. This report confirmed the significance of the combination of geological condition, topographic condition, and structural configurations. Through the investigation, we summarized the reasons of the building collapse and damages in Fig. 29.

Figure 29(a) shows the case on the narrow mountain ridges. The Chautara town belongs to this type. Because the ridge is narrow, buildings used nonhomogeneous foundations. One side of the building is directly located on the ground, and the other side is supported by piles, bricks, or concrete structures. Generally, the mountain ridge experienced stronger shaking, and this may cause the failure at the outside foundations. If the outside foundation is located in a landslide area, the foundation will be prone to collapse even if the landslide does not show obvious displacement; if all of the mountain ridge is located in a landslide, the amplified shaking can cause any types of failure because the ground shaking may cause not only horizontal displacement or vertical displacement, but also rotational displacement. The building damage


Fig. 26 Main cliff from where the rockfall occurred and the landslide dam (a) and the open channel of the collapsed landslide dam (b) 


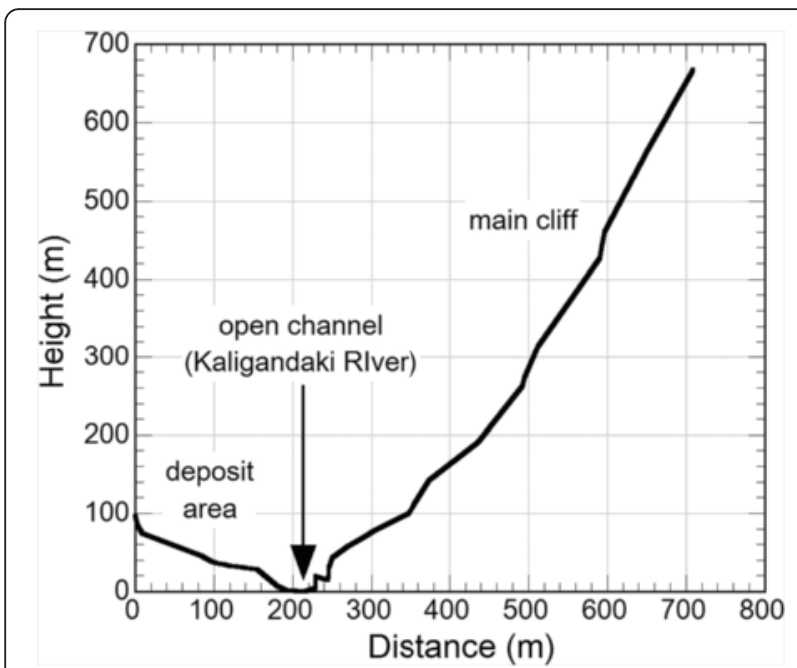

Fig. 27 Main longitudinal section of the collapsed landslide dam and the main cliff after the rockfall

occurred in Gorkha Palace and Changu Narayan were mainly caused by the strong shaking due to the topographic amplification as they are almost at the center of the mountain ridges. The situation at the Swyambhunath World Heritage site is not fully understood, however, at least the failure distribution on the main temple in the center and minor temples closing to the slopes coincided with type (a) in Fig. 29.

Figure 29(b) represents the geological structure in Sankhu town. In the upstream side, gravels and surface water is abundant, while as it goes to downstream side, the grain size of the soil becomes finer and finer, surface water becomes to groundwater, and the groundwater gradually becomes deeper. The reason for the concentrated building damage in Sankhu town may be resonance effect of the buildings to the deposit layers.

Figure 29(c) shows the failure pattern at Purano Naikap area. The similar pattern may be widely distributed around the Kathmandu basin. In this kind of area, the structure of the lacustrine deposit overlaying the bedrock can form an enhanced structure for the occurrence of landslides. If there is no earthquake, the gentle slopes are good for agriculture and housing. However, during a large earthquake, existing landslides can be reactivated. Because the lacustrine deposit landslide mainly consists of clay, generally they will not move for long distance during earthquake, but they can amplify the vibration and cause general destruction to the buildings, especially if the buildings in this area were located on shallow foundations on cut-slopes at the upper side, and infilled ground at the lower side. The amplified shaking may cause intensive settlement at the infill and cause nonhomogeneous deformation at the foundation. When a building is located at the boundary of a landslide, it will suffer much more severe damage.

\section{Conclusions}

Through the one-week field investigation on the housing damage caused by the 2015.4.25 Gorkha earthquake, considering the effects of topographic condition, geological condition, and the building style to the building damages, we found that geological and geomorphological characteristics of a site, combined with the structure of the building, such as the short column effect, selectively amplified the seismic vibration and caused severe building collapse and damages.
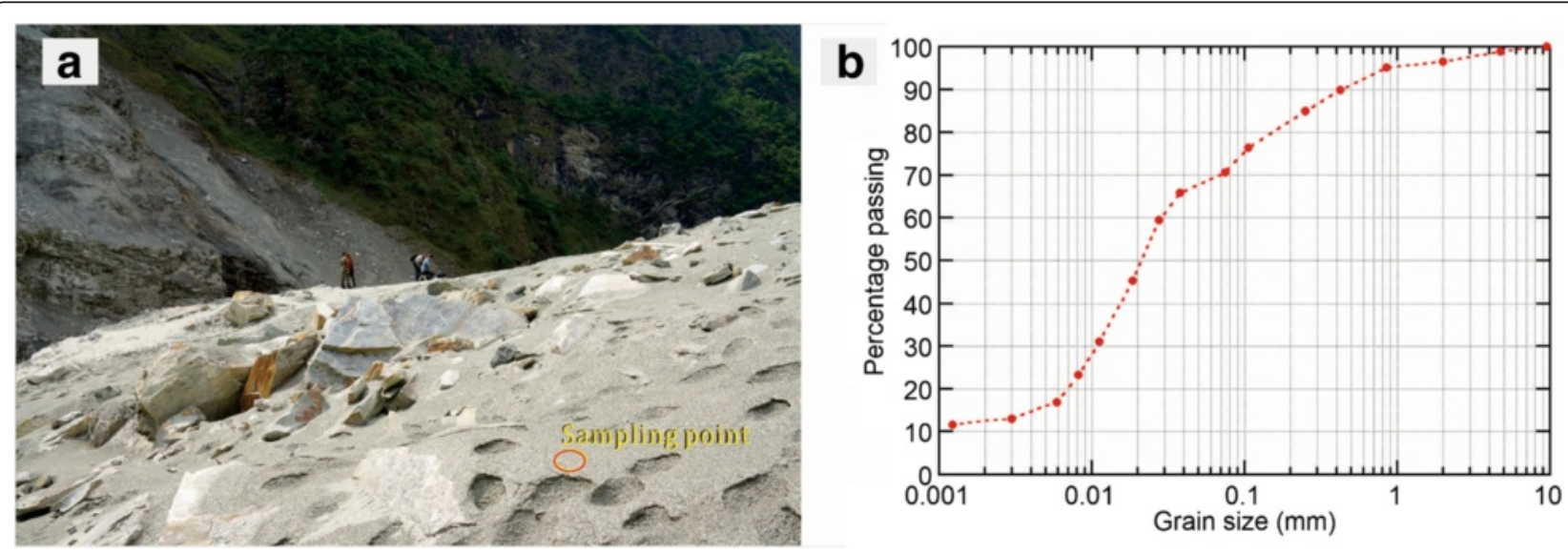

Fig. 28 Fine particles covering the landslide dam. a Photograph taken on 4 June 2015; b grain size distribution of the sample taken from the surface of the landslide dam 


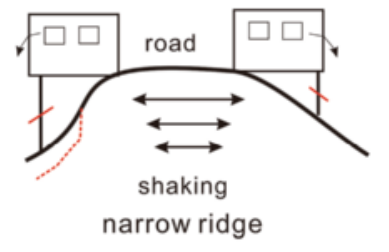

a

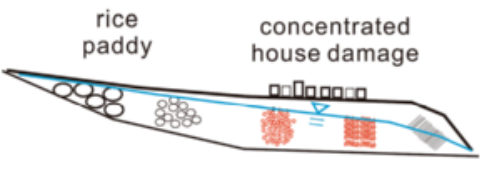

diluvial deposit and alluvial fan

b

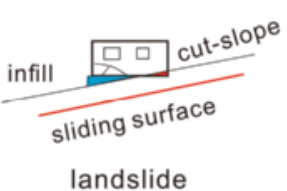

C

Fig. 29 Three main patterns caused the building collapse and damages in 2015.4.25 Gorkha earthquake. a Building damage along narrow mountain ridge; $\mathbf{b}$ concentrated building damage on alluvial fan; and $\mathbf{c}$ building damage on existing landslide

1) For buildings on flat area consisting of lacustrine deposit or diluvial deposit, resonance effect may be the main reason, while for the buildings on the top of hills or narrow ridges, topographic effect and sometimes, short column effect should take the main responsibility;

2) For buildings located on the gentle slopes or landslides, the settlement in the infill side caused by the strong seismic vibration can be the main reason;

3) Besides of the building failure on lacustrine deposit, failure patterns in three types of topographic and geological features, i.e., narrow ridges formed by landslides, diluvial deposits and alluvial fans, and landslides, are proposed as the possible mechanisms of the building damage caused by the earthquake.

4) For landslide dam failure, it is found that landslide dam will easily breach or collapse, when the landslide-dam-deposits are fine. The Kaligandaki landslide dam failure event gave us a good lesson that geo-environmental disasters can be reduced by catching the precursory phenomena and necessary managements.

\section{Competing interests}

The authors declare that they have no competing interests.

\section{Authors' contributions}

FW, MM, RD, MT, TL, MF, YK, and QZ participated the field investigations. FW drafted the manuscript. MT prepared the topographic maps. All authors read and approved the final manuscript.

\section{Acknowledgements}

This work was financially supported by JSPS KAKENHI Grant Number A2424106 for landslide dam failure prediction (Principal Investigator: Fawu Wang). International Consortium on Geo-disaster Reduction (ICGdR) also financially supported the field investigation. Mr. Tek Bahadur KC, the Chief District Officer of Beni and Mr. Uddhab Prasad Timalsena, the Chief District Officer of Gorkha, kindly gave us permission and supported our investigation. The authors thank Lynn Highland of USGS for her helpful and constructive comments on the contents when the first author presented the results in GSA2015 in Baltimore, USA. She also reviewed and edited the first manuscript of this paper.

\section{Author details}

'Department of Geoscience, Interdisciplinary Graduate School of Science and Engineering, Shimane University, Nishikawatsu 1060, Matsue 690-8504, Japan. ${ }^{2}$ Faculty of Environmental Design, Kanazawa University, Kakuma, Kanazawa 920-1192, Japan. ${ }^{3}$ Himalayan Geo-disaster Research Center, Central Department of Geology, Tribhuvan University, Kirtipur, P.O. Box 9669, Kathmandu, Nepal. ${ }^{4}$ Nepal Himalaya Conservation Group, P. O. Box 9669,
Kathmandu, Nepal. ${ }^{5}$ College of Geological Engineering and Geomatics, Chang'an University, 126 Yanta Road, Xi'an 710054, China. ' Interdisciplinary Graduate School of Science and Engineering, Shimane University, Nishikawatsu 1060, Matsue 690-8504, Japan.

Received: 23 December 2015 Accepted: 29 April 2016 Published online: 10 May 2016

\section{References}

Collins BD, Jibson JW. 2015a. Assessment of existing and potential landslide hazards resulting from the April 25, 2015 Gorkha, Nepal earthquake sequence. USGS Open-File Report 2015-1142.

Collins BD, Jibson JW. 2015b. Ground-shaking in the steepest terrain on Earth: landslides from the 2015 Gorkha, Nepal earthquake sequence. Geological Society of America Abstracts with Programs. 47(7): 608.

Dahal RK, Timilsina M. 2015. Excursion Guidebook for the 2015 Gorkha Earthquake Damage Assessment Program. ICGdR, 29p.

Goda, K., T. Kiyota, R. Pokhrel, G. Chiaro, T. Katagiri, K. Sharma, and S. Wilkinson. 2015. The 2015 Gorkha Nepal Earthquake: Insights from Earthquake Damage Survey. Frontiers in Built Environment 1: 8. doi:10.3389/fbuil.2015.00008.

Hashash YMA, Tiwari B, Moss RES, Asimaki D, Clahan KB, Kieffer DS, Dreger DS, Macdonald A, Madugo CM, Mason HB, Pehlivan M, Rayamajhi D, Acharya I, Adhikari B. 2015. Geotechnical Field Reconnaissance: Gorkha (Nepal) Earthquake of April 252015 and Related Shaking Sequence. Geotechnical Extreme Event Reconnaissance GEER Association, Report No. GEER-040. Version 1.0, 250p

Murty CVR. 2016. Why are Short Columns more damaged during Earthquakes? http://www.iitk.ac.in/nicee/EQTips/EQTip22.pdf\#search=\%27short +column\%27 (last visit: 5 April 2016).

Pandey, V.K., and A. Mishra. 2015. Geoenvironmental impact of Gorkha earthquake, Nepal: April- May, 2015. International Journal of Engineering Sciences \& Management Research 2(7): 50-57.

Paudyal, Y.R., R. Yatabe, N.P. Bhandary, and R.K. Dahal. 2012. A study of local amplification effect of soil layers on ground motion in the Kathmandu Valley using microtremor analysis. Eartha Engineering and Engineering Vibration 11: 257-268.

Sakai, H. 2001. Stratigraphic division and sedimentary facies of the Kathmandu Basin Group, central Nepal. Journal of Nepal Geological Society. 25(Special Issue): 19-32.

Singh Y, Lang DH, Narasimha DS (2015) Seismic risk assessment in hilly areas: case study of two cities in Indian Himalayas. Proc. SECED 2015 Conference: Earthquake Risk and Engineering towards a Resilient World 9-10 July 2015, Cambridge UK, SINGH_LANG_NARASIMHA.pdf, 1-10.

USAID. 2015. Nepal Earthquake - Fact Sheet \#20, https:/www.usaid.gov/nepalearthquake/fy15/fs20. (last visit: 5 April 2016). (on June 12, 2015).

Wikipedia. 2015: https://en.wikipedia.org/wiki/Dharahara. (last visit: 5 April 2016). 